\section{EL TRABAJO REMOTO Y EL DESEMPEÑO LABORAL EN EL MARCO DEL COVID-19}

TELECOMMUTING AND LABOR PERFORMANCE ON COVID-19 FRAMEWORK

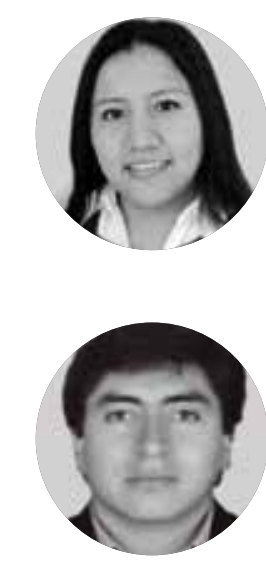

Victoria Judith Chuco Aguila

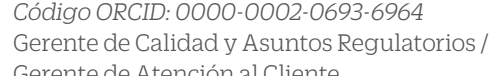

Gerente de Atención al Cliente
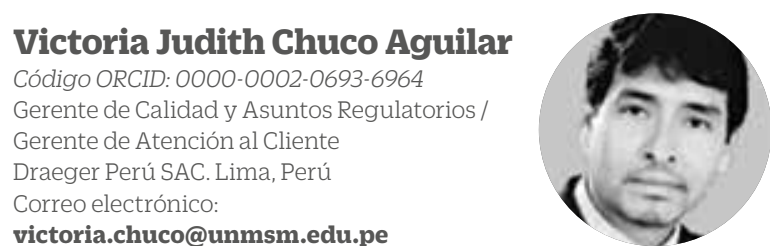

José Antonio Álvarez Pejerrey

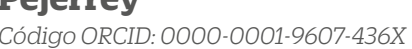

Docente
UNMSM. Lima, Peru

Manuel Greck Anderson Chávez Ramírez

Codigo ORCID: 0000-0001-8812-5112
Director
Instituto Americano de Investigación Desarrollo. Lima, Pe.

manuel.chavez@unmsm.edu.pe

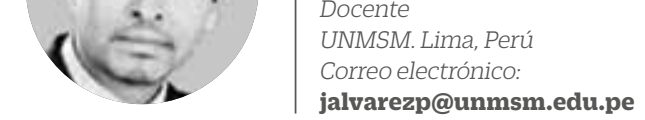

Recibido: setiembre, 2020

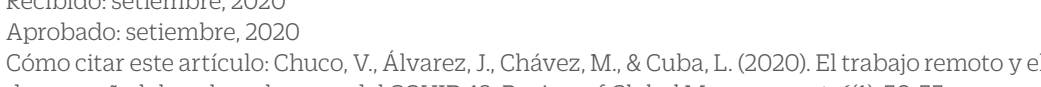

Cómo citar este artículo: Chuco, V. Allvarez, J., Chávez, M. . \& Cuba, L. L. (2020). El trabajoj remoto
RESUMEN

El teletrabajo busca que los trabajadores puedan realizar sus labores de forma remota. En un contexto de pandemi por la cov 19 , l teletrabajo se haconvertido en la principa es los trabar a e los trabajadores, debido las prestones laborales y ta inportantes emergen en este análisis b. Dos factores (n) modalidad para desarrollar las labores en las organizaciones adecuados y la capacidad del trabajador de manejar sus

Palabras clave: Teletrabajo, COVID-19, productividad.

ABSTRACT

Telecommuting allows employees to do work from home Telecommuting become the main working mode in organizations. This fact represents a challenge for maintaining employee productivity, due to labor pressures and market uncertainty Two main factors emerge from this analysis: the organization capacity to establish adequate communication systems, tions under uncertainty

Keywords: Telecommuting, COVID-19, productivity

I. PLANTEAMIENTO DE LA INVESTIGACIÓN

1.1 Introducción

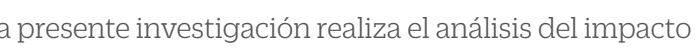
que ha causadola pandemia del coronavirus. Se ha revisado

\section{a) Situación problemática}

El virus SARS-COV2 se dispersó por muchas naciones

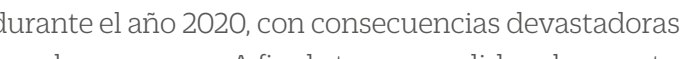
presidente de Perí anunció un estado de en al 5 de marzo Como consecuencia de esta medida much actividades productivas interrumpieron sus labores Otras organizaciones cambiaron su modalidad de trabajo es decir de la modalidad presencial al trabajo remoto cara Por tanto, los empleados tuvieron que adaptarse a las nuevas circunstancias. En consecuencia, este cambio de modalidad impactará en su desempeño, pues disminuir se mantendrả estable o incluso mejorara

) Principales antecedentes de la investigación: causas y caractesistro las modalidades del teletrabajo, que definitivamentices propias, ademas delids durante mplementacín ten que ser conocilosinado con el tiempo. Los hallazgos obtenidos en el trabajo señalan que la implementación del teletrabajo como modalidad laboral conlleva que la organizacion obtenga un aumento de la productividad, menores costos y menor absentisma lo seciarich dizacion de las tecnologias de la hiformacion. Además. más sencilla de mplementar porque va a gonera un equilibrio perfecto, porque los teletrabajadores pueden desarrollar sus tareas fuera de las instalaciones de organización durante doso tresdias de la semana, sin sacrificar el contacto con sus compañeros de trabajo ni el sentido de pertenencia a su organización.

Ardila (2015) realizó un estudio referente a los efectos del teletrabajo en los resultados de la gestión en una organización financiera en Bogota, a fin de determinar los efectos de la ejecución del trabajo remoto en los resultados de la dirección organizacional, empleando un análisis de investigacion de campo en una organización de la industria financiera de la ciudad de Bogotá en el año 2013, trazando un paralelo entre el trabajo tradicional y el teletrabajo. Como resultado de la investigacion se pudo determinar que, mediante una adecuada dirección, el impacto generado por la implenentación del teletrabajo de la orgnización permite conizidecon las expectativas

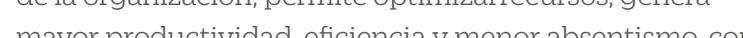
una adecula gestión administrativa Los teltrabajeres resaltan como características destacadas el poder compartir más tiempo con la familia el mejoramiento de su calidad de vida el ahorro en tiempo y dinero en desplazamientos y el auxilio mensual a que tienen derecho por pertenecer a teletrabajo.

Araníbar Díaz (2016), por su lado, demostró que es posible reducir el costo y mejorar la productividad de esta actividad mediante la aplicación de este modelo de trabajo, como alternativa viable de solución para la contaminación ambiental. Los hallazgos de este trabajo mostraron que la implementacion del teletrabajo en la consultoría informática reduce los costos de la consultoria, tanto para el cliente, cono para el consultor. Por otro lado, el teletrabajo aumenta la productividad del consultor en comparación con el sistema presencial; bajo estas estas circunstancias, la productividad se incrementó en un 13\%. Los niveles de estres que experimentan las personas, producido por el viaje dianio que realizan al trabajo, es menor cuando realizan sus labores medante trabajo remoto, los consultores que teletrabajaron evitaron enplear 113.30 horas por

\section{c) Importancia o fundamento: Justificación}

- Teórica

El presente artículo tiene por objetivo abordar aspectos 
teóricos en referencia al trabajo remoto y el desempeño laboral. De ese modo, se podrá contrastar si los conceptos $\mathrm{y}$ antecedentes abordados permiten describir la teniendo en cuenta el contexto de la pandemia de COVID-19.

\section{•Práctica}

Como resultado del Estado Nacional de Emergencia declarado en Perú el 15 de marzo de 2020, mediante Decreto Supremo 044-2020-PCM, las empresas peruanas tuvieron que evaluar si sus actividades se podia realiza remotamente. Esto puede generar un cambio en el desempeño laboral de sus colaboradores. Por ello, los resultados de este articulopueden ser empleados para aspectos que conlleva la modalida de trabajo remoto.

\section{d) Marco teórico}

Tras el descubrimiento del virus SARS-CoV-2 en China los médicos e investigadores Rothe, Schunk y otros (Rothe et.al, 2020) advirtieron que este nuevo virus proveniente de Wuhan causa gran preocupación en el mundo Desde que se identificó el virus. a fines de diciembre de 2019. la cantidad de casos en China que importarona otros píses ha aumentado constantemese y el ámbito epidemiológico cambia diariamente.

La masiva movilidad global de las personas y el tráfico intercontinental de pasajeros a diversas latitudes ha permitido que el virus se propague, llegandoa América Latina y el Perú. Este escenario motivó que el Gobierno peruano dicte el Decreto Supremo No 008-2020-SA, con fecha 11 de marzo del 2020, el cual declara la emergencia sanitaria a nivel nacional por 90 dias, estableciendo diversas medidas de prevencion y control para evitar propagación de la COVID-19

Las medidas tomadas por el gobierno de turno no fueron las adecuadas, pues la cantidad de casos confirmados aumentó vertiginosamente. Es así como la Sala situacional COVID-19 Perú reportó, al 25 de mayo de 2020, 123,979 casos confirmados. Respecto a la propagación de este virus Trilla (2020) menciona que es muy probable que a covid-19 se propague a traves de contacto, gotas además de fómites contaminados por este tipo de aerosoles. Agrega que la transmisión por vía aérea no se puede descartar por completo. El contacto prolongado presenta un mayor riesgo de contagio, y menor riesgo en caso de contacto casual.

Lo antes señalado permite afirmar que los contagios de este virus no solo se realizan a través delas personas sintomáticas, sino también por las asintomáticas,

situacion que obliga a las enpresas de cualquier tamaño, a buscar modalidades de trabajo alternativas a la presencialidad, introduciendo el teletrabajo y el trabajo remoto como una solucion. Asimismo, se debe tener en cuenta que las pequeñas y microempresas, en su mayoría, carecen de recursos para ejecutar protocolos especiales de seguridad cantalla para herar elcontagiode sus trabaja

\section{Base Legal Decretada por el Poder Ejecutivo durant} el Estado de Emergencia

作 2020, que declara la emergencia sanitaria a nivel diversas medidas de prevención y

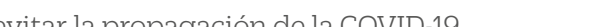

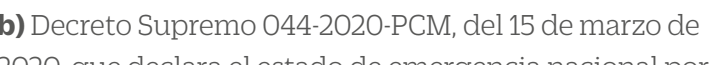
2020, que declara el estado de emergencia nacional por social (cuarentena), por las circunstancias criticas que afectan la vida de la nación comoconsecuenciade la pandemia de COVID-19.

c) Decreto Supremo 051-2020-PCM, promulgado el 27 de marzo de 2020, que amplia el Estado de Emergencia Nacional declarado por el Decreto Supremo 044-2020PCM, por el lapso de 13 días calendario, a partir del 31 de marzo de 2020

d) Decreto de Urgencia 026-2020, del 15 de marzo de 2020, que establece diversas medidas excepcionales y temporales para prevenir la propagación de la CoviD-19 en el territorio nacion

e) Resolución Ministerial 072-2020-TR, del 26 de marzo de 2020, que aprueba el documento denominado «Guía

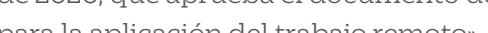

\section{Formas Alternativas de Trabajo}

El Decreto de Urgencia 026-2020, el Decreto Suprem

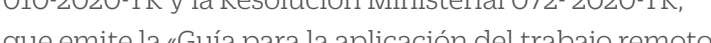

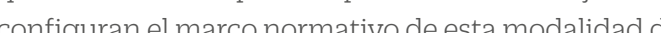

trabajo, cuyo estudio es esencial en el ámbito académico para su aplicación por parte de las diversas organizaciones principalmente en el caso de las micro y pequeñas empresas, las cuales se enfrentan al reto de mantenerse operativas y dar trabajo a sus empleados, ya que si no cuentan con alternativas para poder realzar sus

Para conocer el onigen del trabajo remoto es necesario remontarse a 1973, cuando el ingeniero de la NASA Jack Nilles planteo el trabajo de forna remota para evitar problemas por desplazamiento debido al exceso de trá́fico y consumo de energía. Es en este contexto, que se generan los primeros intentos de promover el trabajo remoto. Es asi como, el 2 de septiembre de 1979, se publifa en el dianio Washington Post el articulo de Frank W. schiffttulado whe cual pro ento dyor Posterior de trabajo remoto entre ag cins gume Años despús en2004 el Congreso de Estados Unidos se presenta un proyecto de ley que promueve el trabajo remoto en las agencis federales (De Carlo 2017, como citó en Coba 2020)

Esta modalidad de trabajo continuó extendiéndose en el gobierno estadounidense, luego se extendió al se privado. Suárez (s.f.) cita un informe de la empresa Buffer realizado en cooperación con Workfrom. Hubstaft Trello y Doist, la cual destaca que el 43\% de la población activa en los Estados Unidos trabaja de forma remo Asimismo, el autor estima que para el año 2035, se contará con mil millones de nómadas digitales en tod。 el mundo.

Cabe señalar que el trabajo remoto o teletrabajo es un tendencia en desarrollo en el mercado laboral mundial. Respecto a la definición de este término, Moreno (2012) señala que el trabajo remoto es la prestación de una actividad laboral, la cual se realiza principalmente en el hog del trabajador och un lugar pubico elegido por este. contra recrón han establecido los conposestes neces para los paradignas de espacio tiempoen laue se realizata el trabajo de oficina convencional, permitiendo que se abra paso a una nueva modalidad de trabajo que permita al trabajador realizar sus labores desde cualquier lugar en el mundo (Sapién-Aguilar, Carrera-Ramos, Piñón-Howlet, \& Gutiérrez-Diez, 2016).

Sin embargo, es necesario tener en cuenta los retos que conlleva el desarrollo de esta modalidad de trabajo, a fin de evitar que conlleve hacia una mayor precariedad labo. ral. En el mismo sentido, Vocos y Martinez (2004), señalan que esta modalidad puede ser utilizada para a) cambios potenciales en los derechos y condiciones de contratación b) aumentar los riesgos a la salud; c) consecuencias en el ámbito extra-laboral; d) debilitamiento de los colectivos

\section{Nuevos Retos en la Gestión empresarial}

La propagación del CoVID-19 nos enfrenta a un escenario antes desconocido, pues aunque el trabajo remoto conserva la característica de subordinación a través de la presencia física del trabajador desde su hogar o lugar de aislamiento, se requiere de herramientas o mecanismos quele permitan realizar sus actividades mediante programas informáticos, conexión a internet, acceso a bases de datos adicional por parte de la empresa. Es necesario agregar que esta es una medida temporal mientras se supere crisis sanitaria debido a la pandemia global.

Además, en relación con el efecto socioeconómico de la pandemia por el nuevo virus SARS-CoV-2, la Organización Internacional del Trabajo (OIT) invoca al respeto, la promocion y el cumplimiento de los Principios y Derechos Fundamentales en el Trabajo. En ese sentido, la OIT hace un llamado para tener en consideración a los grupos sociales y personas en situacion de vulnerabilidad como consecuencia de la crisis sanitaria (International Labour Organization, 2020). En esa linea, el gobierno de Martín Vizcarra lanzo un plan para subsidiar el sueldo de los empleados no esenciales, cuyos trabajos han sido paralizados a causa de la emergencia sanitaria, ademas de los pagos (Horwitz et al., 2020).

\section{Consideraciones en torno al trabajo remoto}

Debido a que diversas actividades no están condicionadas a la presencia física en las oficinas de las empresas, éstas 
serán desarrolladas con el respaldo de la tecnología. Entre esas actividades tenemos: el diseño instruccion de programas de estudio, virtualización de contenido, la instrucción síncrona, marketing digital entre otras De otro lado, las micro y pequeñas empresas están implementando cambios en sus procesos de trabajo para mantener en marcha su cadena de producción y así evitar el cierre definitivo de operaciones.

El trabajo remoto permite mantener la operatividad de las empresas, sin transgredir las normas dictadas por Poder Ejecutivo, mientras se reanudan las actividades comerciales; y se garantice que el personal no esté expuesto al contagio del COVID-19, al restringir la interaccion fisica y la cercanific con personas asintomáticas De acuerdo con Anghel, Cozzolino y Lacuesta (2020). se evidencia un mayor interés por el trabajo remoto por partede las eminesas, debido al aunnento de podría generar.

Sin embargo, las evidencia no es concluyentes en cuanto podría ser útil para trabajos creativos y al mismo tiempo ser periudicial para tareas urgentes y complejes. Como señala Morikawa (2020) el efecto negativo sobre la productividad podrí verse afectado en un contexto de pandemia y aislamiento, como resultado de inversimadecuadas en capacitacion de competencias

\section{CONCLUSIONE}

La pandemia por el nuevo virus SARS-CoV-2 ha cambiado los entornos de trabajo, al trasladarse el trabajo desde las oficinas a los hogares.. El trabajo remotoha obligado a los trabajadores a trabajar más tiempo desde casa. Las tasas de productividad de estos trabajadores se ven significativamente afectadas en esas circunstancias. El crecimiento chario de la carga de trabajo, junto a la incertidumbre respecto a la situación laboral, podría suponer un revés para la productivdad de los empleados. ta razon más

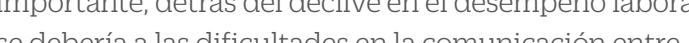
trabajadores pues el trabaio en equipp rection entre comunicación efectiva Un trabajador requiere contar con pautas especificas sobre las actividades a realizarse, cuál es el propósito de sulabor y las expectativas de los clientes No se puede garantizar niveles adecuados de calibración del trabajo si no se establecen vías de comunicación idóneas entre trabajadores, los cuales se encuentran en distintas ubicaciones para alcanzar un objetivo en común. Por consiguiente, de no garantizarse una comunicación efectiva entre los trabajadores de la empresa, se afectarála productividad.

En la misma línea, un eventual problema de salud del trabajador o de su familia podría reflejarse en falta de concentracion en el trabajo, lo que afectará su productividad Asimismo, podria ser muy agotador emocionalmente cuando los colaboradores desempeñan el rol de padres de familia paralelamente. Adicionalmente, la falta de acceso a recursos del entorno de trabajo obstaculizará el alcance de los objetivos de la crgar

Por consiguiente, es deber del equipo de recursos humanos tomar conciencia de las condiciones que enfrentan los 作 esta nueva modalidad de trabajo. Algunas medidas que se deben tener en cuenta para mitigar el impacto negativo de esta modalidad de trabajo son talleres o charlas respecto al equilibro familia-trabajo, así como la orientación de un para mejorar el bienestar del trabajador

\section{REFERENCIAS}

Anghel, B., Cozzolino, M., \& Lacuesta, A. (2020). El teletrabajo en España (Artículos analiticos No.2). Boletín económico del Banco de España. Recuperado de https://repositorio.bde.es/handle/123456789/

Aranibar Díaz, A. A. (2016). Mejoramiento de la productividad y minimización de costos de la consultoría informát mediante el modelo de teletrabajo (Tesis para optar el titulo profesional de Ingeniero Empresarial

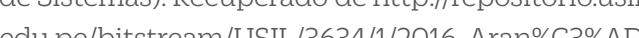
bar-D\%C3\%ADaz.pdf
Ardila, C. O. (2015). Análisis del impacto del teletrabaio en los resultados de gestión de las organizaciones Estudio de caso en un área de una organización financiera en Bogotá (Trabajo de grado para obtener el título de Maestro en Gestión de Organizaciones). Recuperado de https://repositoryunimilitar.edu.co/ handle/10654/14011

Coba, F. M. T. (2020). Trabajo remoto en procesos no urgentes a consecuencia del brote del coronavirus (COVID-19) en el Peru y su aplicacion continua. Revista Oficial del Poder Judicial. Organo de Investigación de la Corte Suprema de Justicia de la República del

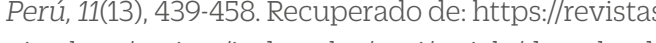
pj.gob.pe/revista/index.php/ropj/article/download/ 531108

Horwitz, L., Nagovitch, P., Sonneland, H. K., \& Zissis, C. (2020). Where Is the Coronavirus in Latin America? AS/COA. Archived from the original on, 22. Recuperado de 8f853bce65a48e3112bb75a48cbfff26ab.pdf

International Labour Organization. (2020, 8 de abril). The socio-economic impact of COVID-19 in fragile settings: Peace and social cohesion at risk. Recuperado de https://www:ilo.org/global/topics/employment 7. 74158/ecovery-and-reconstructio/

Montes Cato, J., Palermo, H., Spinosa, L., \& Ventrici, P. (2020) La situación del empleo en Argentina durante el aislamiento social. preventivo y obligatorio [Informe] Centro de Estudios e Investigaciones Laborales CONICET. Recuperado de http://www.ceilconicet.go ar/2020/05/informe-la-situacion-del-empleo-enargentina-durante-elaislamiento-social-preventivoy-obligatorio/

Moreno, M. N. (2012) Novedades en materia de modalidades contractuales: contrato indefinido para pequeñas empresas, trabajo a tiempo parcial y trabajo remoto Temas laborales: Revista andaluza de trabajo y bienestar social, (115), 193220. Recuperado de https//

Morikawa, M. (2020, 10 de abril). Covid-19, teleworking, and productivity The Centre for Economic Policy
Research. Recuperado de https://voxeu.org/article/ covid-19-teleworking-and-productivity

Ortega, L. F. (2017). Teletrabajo: una opción para la mejora de los beneficios de las organizaciones y de los https://repository.usta.edu.co/handle/11634/2880

Rothe, C., Schunk, M., Sothmann, P., Bretzel, G., Froeschl, G., Wallrauch, C.,... Hoelscher, M. (2020). Transmission of 2019-nCoV infection from an asymptomatic contact in Germany. The New England Journal of
Medicine, (382), 970-971. doi:10.1056/NEJMc2001468

Sapién-Aquilar, A. L., Carrera-Ramos. M. Piñón-Howlet, L C. \& Gutiérrez-Diez, M. (2016). Competencias de tecnologia de informacion para el trabajo remoto en las organizaciones en Mexico. Publicaciones, 46, 1147. Recuperado de http.//revistaseugug

Schiff, F. W. (1979, 2 de setiembre). Working at home can save gasoline. The Washington Post. Recuperado de https://wwwwwashingtonpost.com//archive/opinions -home-can-save-gasolin

Suárez, C. J. (s.f.). Conferencia sobre trabajo remoto repeople Conference 2020 (Publicación web). Recuperado de

Trilla, A. (2020). Un mundo, una salud: la epidemia por el nuevo coronavirus COVID-19. Medicina Clinica, 154(5) 175-177. doi: 10.1016/j.medcli.2020.02.002

Vocos, F., \& Martinez, O. A. (2004). Teletrabajo: Lotro canto de sirenas? El movimiento obrero frente a una nueva estrategia empresaria (Cuadernos del TEL). Buenos Aires, Argentha. Taller de Bstudos Laborales. Recuperado de http://www.tel.org.ar/spip/descarga/ teletrabajo.pdf 